\title{
Bevacizumab for metachronous metastatic colorectal cancer: a reflection of community based practice
}

\author{
L. G. E. M. Razenberg ${ }^{1,2^{*}}$, Y. R. B. M. van Gestel' ${ }^{2}$, I. H. J. T. de Hingh ${ }^{3}$, O. J. L. Loosveld ${ }^{4}$, G. Vreugdenhil' ${ }^{5}$,
}

L. V. Beerepoot ${ }^{6}$, G. J. Creemers ${ }^{1}$ and V. E. P. P. Lemmens ${ }^{2,7}$

\begin{abstract}
Background: Although the efficacy of bevacizumab has been established in patients with metastatic colorectal cancer $(\mathrm{mCRC})$, population-based studies are needed to gain insight into the actual implementation of bevacizumab in daily practice. Since these studies are lacking for patients with metachronous metastases, the aim of this study is to evaluate the current role of bevacizumab in the treatment of metachronous metastases of CRC.

Methods: Data on the use of bevacizumab as palliative treatment of metachronous metastases were collected for patients diagnosed with MO CRC between 2003 and 2008 in the Eindhoven Cancer Registry $(n=361)$. Median follow up was 5.3 years.

Results: One hundred eighty-five patients received bevacizumab in addition to first-line palliative chemotherapy $(51 \%)$, ranging from $36 \%$ to $80 \%$ between hospitals of diagnosis $(p<0.0001)$. Combined cytostatic regimens (CAPOX/FOLFOX in $97 \%$ ) were prescribed in the majority of patients (63\%) and were associated with a higher odds for additional treatment with bevacizumab than single-agent cytostatic regimens (OR 9.9, 95 \% Cl 5.51-18.00). Median overall survival (OS) rates were 21.6 and 13.9 months with and without the addition of bevacizumab to palliative systemic treatment respectively $(p<0.0001)$. The addition of bevacizumab to palliative chemotherapy was associated with a reduced hazard ratio for death (HR 0.6, $95 \% \mathrm{Cl} 0.45-0.73)$ after adjustment for patient- and tumor characteristics and the prescribed chemotherapeutic regimen.

Conclusion: Bevacizumab is adopted as a therapeutic option for metachronous metastasized CRC mainly in addition to first-line oxaliplatin-based regimens, and was associated with a reduced risk of death. The presence of inter-hospital differences in the prescription of bevacizumab reflected important differences in attitude and policies in clinical practice. Ongoing efforts should be made to further define the position of targeted agents in the treatment of metastatic colorectal cancer.
\end{abstract}

Keywords: Colorectal cancer, Metachronous metastases, Palliative, Chemotherapy, Targeted therapy, Bevacizumab

\section{Background}

Metastatic disease is a common manifestation in patients with advanced colorectal cancer (CRC). Approximately one fifth of patients presents with metastasized disease at diagnosis [1-3] and $20 \%$ of patients with initial M0 disease develops metachronous metastases [4].

\footnotetext{
*Correspondence: lieke.razenberg@catharinaziekenhuis.nl

'Department of Oncology, Catharina Hospital, Michelangelolaan 2, 5623EJ,

Eindhoven, The Netherlands

${ }^{2}$ Netherlands Comprehensive Cancer Organization (IKNL), Godebaldkwartier

419, 3511DT, Utrecht, The Netherlands

Full list of author information is available at the end of the article
}

Fluorouracil based palliative chemotherapy has been the mainstay of treatment for many years. Over the past decade, the systemic treatment of metastatic CRC (mCRC) has changed considerably. The availability of the cytostatic drugs irinotecan and oxaliplatin has improved the prognosis of mCRC patients [5]. Moreover, advances in the understanding of molecular oncology have served for the development of targeted agents such as the anti-vascular endothelial growth factor blocking agent (VEGF-a) bevacizumab. Although the efficacy of bevacizumab has been established in patients with $\mathrm{mCRC}$ 
[6], the role of bevacizumab in clinical practice remains a topic of debate. Population-based data are useful in reflecting community based practice. To date, no such population-based figures of patients with metachronous metastases are available. Therefore the aim of this study is to provide population-based data on the use and effect on overall survival of bevacizumab in the palliative treatment of metachronous metastasized CRC in the Netherlands.

\section{Methods}

\section{Patients and data}

Data from the population-based Netherlands Cancer Registry (NCR), more specifically from the Eindhoven area, were used. The Eindhoven Cancer Registry (ECR) collects data of all patients with newly diagnosed cancer in a large part of the Southern Netherlands. The ECR covers an area of approximately 2.4 million inhabitants, six pathology departments, ten hospitals and two radiotherapy institutions. Patient and tumor characteristics are collected from medical records by specially trained registry staff after notification by pathologists and medical registration offices, resulting in high quality of the data. The completeness of cancer registration is estimated to exceed $95 \%$. In the ECR, primary tumors are classified according to the TNM classification of Malignant Tumors by the international Union Against Cancer (UICC), $7^{\text {th }}$ edition [7]. Additional data were retrospectively collected on metachronous metastases for patients diagnosed between 2003 and 2008 with stage I-III CRC. Hospitals were asked to participate in the study by giving permission to use their data from the ECR and by giving permission for the retrospective registration of additional data. All hospitals voluntarily participated.

Metachronous metastases were defined as distant metastases of primary CRC in other organs, diagnosed at least 3 months after CRC diagnosis. However, the majority of metachronous metastases diagnoses (94\%) occurred at least 6 months after CRC diagnosis. Patterns of metastatic disease were determined based on the site of metastasis according to the International Classification of Diseases for Oncology (ICD-O), which could involve multiple localizations. Median time from primary diagnosis to data collection was 5.3 years (range $1.5-8.8$ years). All consecutive patients with metachronous metastases from primary resected CRC were selected $(n=1010)$. Patients diagnosed with metachronous metastases before 2005 $(n=100)$ were excluded as bevacizumab is registered and recommended as a therapeutic option in addition to first-line chemotherapy in the Netherlands since 2005 [8]. Subsequently, patients undergoing surgery for metastases were excluded $(n=232)$, resulting in a study population treated with palliative intent $(n=678)$ of whom 361 received palliative chemotherapy (with or without palliative procedures; bypass, anastomosis, stoma). These latter patients were categorized into two treatment groups according to the prescription of bevacizumab in addition to palliative chemotherapy (Fig. 1). In the current study, we focused on the first-line palliative treatment as this is the indication for which bevacizumab is registered in the Netherlands.

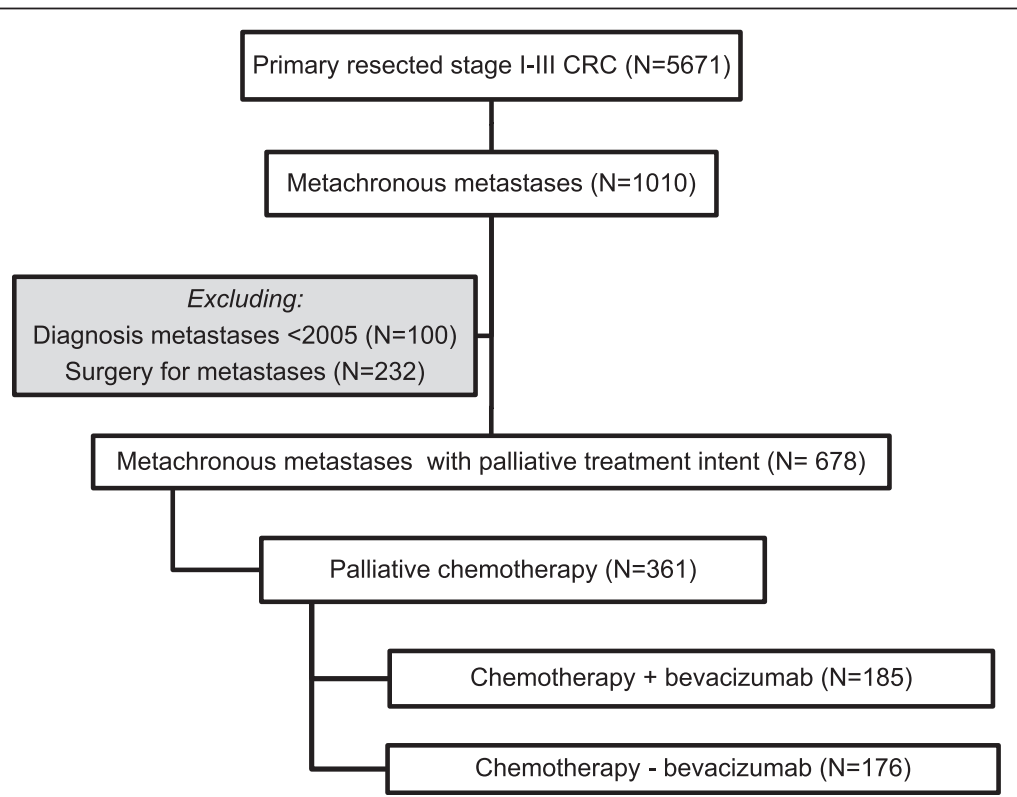

Fig. 1 An overview on the palliative systemic treatment of metachronous metastases for patients diagnosed between 2003 and 2008 with stage I-III colorectal cancer in the south of the Netherlands 


\section{Statistical analysis}

Variation in the prescription of bevacizumab between hospitals of diagnosis in the ECR-region was assessed using a $X^{2}$ test. Also, differences in patient and tumor characteristics and the prescription of bevacizumab between chemotherapeutic regimens were tested by means of a $x^{2}$ test. To discriminate independent predictors of treatment with bevacizumab, a multivariable logistic regression model was used. Adjustments were made for relevant patient and tumor characteristics: gender, age, comorbidity at time of CRC diagnosis, primary tumor localization, adjuvant chemotherapy, time to metastases, period of metastases diagnosis, number of metastases and the prescribed first-line chemotherapeutic regimen. In order to limit potential endogeneity bias due to the population-based nature of the data, a propensity score matched sample was created. Propensity scores were determined with a logistic regression model in which bevacizumab was the variable of interest and the independent variables were factors potentially associated with the use of bevacizumab (similar to variables taken into account in the multivariable logistic regression analysis). Patients were then matched within tight bounds of the propensity scores (probability could vary by no more than $1 \%$ ). Overall survival time was defined as the time from diagnosis of the first metachronous metastatic site to death or lost to follow-up. Patients still alive at the end of follow-up (January $1^{\text {st }}, 2014$ ) and those who emigrated were censored. Crude survival estimates according to the prescription of bevacizumab were calculated with the Kaplan-Meier method and presented up to 48 months in both the total study population and the propensity score matched sample. Median survival (MS) was presented in months and corresponding $95 \%$ confidence intervals (CIs). A log-rank test was carried out to evaluate significant differences between survival curves. Multivariable Cox regression analyses were performed in both the total study population and propensity score matched sample to evaluate the independent effect of additional bevacizumab on the risk of death. Adjustments were made for the clinically relevant variables age, comorbidity, localization of primary tumor, adjuvant chemotherapy, time to metastases, period of metastases diagnosis, number of metastases, prescribed first-line chemotherapeutic regimen and the total number of systemic lines for the treatment of metastases. All analyses were performed with SAS/STAT ${ }^{\circ}$ statistical software (SAS system 9.3; SAS institute, Cary, NC).

\section{Ethical considerations}

In the Netherlands, the NCR and Dutch hospitals have a formal agreement that all cancer patients are informed about registration in the Cancer Registry and the possibility to decline registration. According to the Dutch law, all cancer patients are included in the NCR unless the patient has objected to be registered. Therefore, consent of the patient for this specific study was not applicable.

The NCR retrospectively collects data from medical records and is obligated to work according to laws in which the privacy of patients and doctors is fixed in regulations; the law about protection of privacy and the law "Geneeskundige BehandelOvereenkomst". An independent Committee of Privacy reassures that the NCR works compliant to these regulations. In the Netherlands, retrospective studies with data collected from medical charts do not fall under the scope of the Medical Research Involving Human Subjects Act ('Wet Medischwetenschappelijk Onderzoek") as patient integrity is not violated in these studies. Therefore, this study was exempted from further medical ethics review.

\section{Results}

Out of 5671 primary resected stage I-III CRC patients diagnosed between 2003 and 2008, 1010 patients developed metachronous metastases (18\%). In total, 361 patients received first-line systemic therapy for the palliative treatment of metachronous colorectal metastases. Palliative procedures including a diverting stoma, bypass or anastomosis were performed in a minority of the patients $(n=18,5 \%)$. Bevacizumab was prescribed in $51 \%$ of the patients $(n=185)$, with proportions varying from $36 \%$ to $80 \%$ between the 10 hospitals in the ECR region $(p<0.0001$, Fig. 2$)$. An overview of patient and tumor characteristics according to the addition of bevacizumab to first-line systemic therapy is shown in Table 1.

\section{Patient and tumor characteristics}

Of the 361 patients treated with first-line systemic therapy, 219 patients received combination chemotherapy

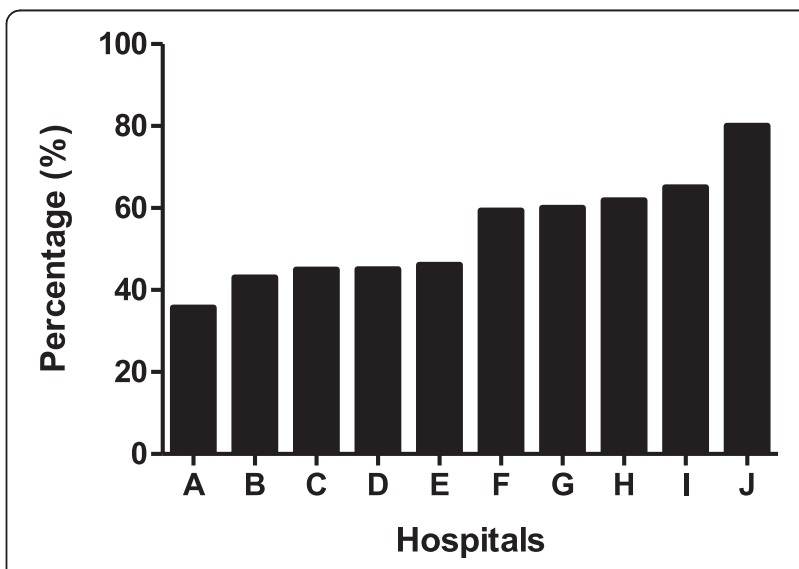

Fig. 2 Proportion of patients receiving first-line palliative chemotherapy plus bevacizumab according to hospital of diagnosis $(n=361)$ 
Table 1 Patient and tumor characteristics according to the addition of bevacizumab to first-line systemic therapy $(n=361)$

\begin{tabular}{|c|c|c|c|c|c|c|c|c|c|c|}
\hline \multirow[t]{2}{*}{$N=361$} & \multicolumn{2}{|c|}{$\begin{array}{l}\text { Without bevacizumab } \\
(n=176)\end{array}$} & \multicolumn{2}{|c|}{$\begin{array}{l}\text { With bevacizumab } \\
(n=185)\end{array}$} & \multirow[b]{2}{*}{$P$-value } & \multicolumn{2}{|c|}{$\begin{array}{l}\text { Combination } \\
\text { chemotherapy }(n=219)\end{array}$} & \multicolumn{2}{|c|}{$\begin{array}{l}\text { Single-agent } \\
\text { chemotherapy }(n=142)\end{array}$} & \multirow[b]{2}{*}{$P$-value } \\
\hline & $\mathrm{N}$ & (\%) & $\mathrm{N}$ & (\%) & & $\mathrm{N}$ & (\%) & $\mathrm{N}$ & (\%) & \\
\hline Gender & & & & & 0.69 & & & & & 0.33 \\
\hline Male & 75 & (43) & 72 & (41) & & 126 & (58) & 89 & (63) & \\
\hline Female & 101 & (57) & 113 & (59) & & 93 & $(42)$ & 53 & (37) & \\
\hline Age (years) & & & & & $<0.0001$ & & & & & $<0.0001$ \\
\hline$<60$ & 36 & (20) & 57 & (31) & & 71 & (32) & 24 & (17) & \\
\hline $60-75$ & 91 & (52) & 111 & $(60)$ & & 128 & (59) & 72 & (51) & \\
\hline$\geq 75$ & 49 & (28) & 17 & (9) & & 20 & (9) & 46 & (32) & \\
\hline Comorbidity & & & & & $<0.001$ & & & & & $<0.01$ \\
\hline No & 50 & (28) & 81 & (44) & & 38 & (28) & 91 & (42) & \\
\hline 1 comorbid condition & 49 & (28) & 56 & (30) & & 36 & (26) & 66 & (30) & \\
\hline$\geq 2$ comorbid conditions & 63 & (36) & 33 & (18) & & 52 & (36) & 44 & (20) & \\
\hline Unknown & 14 & (8) & 15 & (8) & & 14 & (19) & 18 & (8) & \\
\hline Primary tumor localization & & & & & 0.13 & & & & & \\
\hline Rectum & 68 & (39) & 85 & (46) & & 107 & (49) & 47 & (33) & $<0.01$ \\
\hline Colon & 108 & (61) & 100 & $(54)$ & & 112 & (51) & 95 & $(67)$ & \\
\hline Adjuvant chemotherapy & & & & & 0.34 & & & & & $<0.01$ \\
\hline No & 103 & (59) & 100 & (54) & & 137 & (63) & 67 & (47) & \\
\hline Yes & 73 & (41) & 85 & (46) & & 82 & (37) & 75 & (53) & \\
\hline Time to metastases (years) & & & & & 0.12 & & & & & 0.59 \\
\hline$<1$ year & 57 & (32) & 43 & (23) & & 57 & (26) & 42 & (30) & \\
\hline $1-2$ years & 56 & (32) & 71 & (38) & & 82 & (37) & 46 & (32) & \\
\hline$\geq 2$ years & 63 & (36) & 71 & (38) & & 80 & (37) & 54 & (38) & \\
\hline Period of diagnosis metastases & & & & & $<0.01$ & & & & & 0.81 \\
\hline $2005-2006$ & 70 & (40) & 41 & (22) & & 69 & (31) & 42 & (30) & \\
\hline $2007-2008$ & 57 & (32) & 78 & $(42)$ & & 83 & (38) & 52 & (37) & \\
\hline 2009-2011 & 49 & (28) & 66 & (36) & & 67 & (31) & 48 & (34) & \\
\hline Number of organs affected & & & & & 0.29 & & & & & 0.39 \\
\hline 1 organ & 72 & (41) & 85 & (46) & & 92 & $(42)$ & 65 & (46) & \\
\hline 2 organs & 69 & (39) & 59 & (32) & & 83 & (38) & 44 & (31) & \\
\hline$\geq 3$ organs & 35 & (20) & 41 & (22) & & 44 & (20) & 33 & (23) & \\
\hline First-line chemotherapy & & & & & $<0.0001$ & & & & & \\
\hline Single agent chemotherapy & 110 & (63) & 32 & (27) & & & & & & \\
\hline Combination chemotherapy & 66 & (37) & 153 & (83) & & & & & & \\
\hline Bevacizumab & & & & & & & & & & $<0.0001$ \\
\hline Yes & & & & & & 153 & (70) & 32 & (23) & \\
\hline No & & & & & & 66 & (30) & 110 & (77) & \\
\hline
\end{tabular}

(CAPOX/FOLFOX in $96 \%$ ) and 142 patients received single-agent chemotherapy (capecitabine $74 \%$, irinotecan $20 \%$ ). Patient and tumor characteristics of patients treated with these chemotherapeutic regimens are shown in Table 1. Patients receiving combination chemotherapy were younger, had less comorbidities, were more often diagnosed with rectal tumors and less often received prior adjuvant chemotherapeutic treatment than patients receiving single-agent chemotherapy. Moreover, patients treated with combination chemotherapy more frequently received bevacizumab $(n=153,70 \%)$ than patients treated with single-agent chemotherapy $(n=32,23 \%, p<0.0001)$. 


\section{Predictors of treatment with bevacizumab}

In multivariable regression analysis including adjustment for the type of prescribed first-line chemotherapeutic regimen, several factors were shown to influence the probability to receive additional first-line bevacizumab (Table 2). It was confirmed that patients treated with

Table 2 Proportion of patients treated with bevacizumab among patients who received chemotherapy, and predictors of treatment with bevacizumab in first line, adjusted for all factors listed $(n=361)$

\begin{tabular}{|c|c|c|c|c|}
\hline$N=361$ & $\mathrm{~N}$ & (\%) & OR & $95 \% \mathrm{Cl}$ \\
\hline \multicolumn{5}{|l|}{ Gender } \\
\hline Male & 72 & (49) & Ref & \\
\hline Female & 113 & (53) & 1.3 & $0.79-2.16$ \\
\hline \multicolumn{5}{|l|}{ Age (years) } \\
\hline$<60$ & 57 & (60) & Ref & \\
\hline $60-74$ & 111 & (56) & 1.1 & $0.61-2.05$ \\
\hline$\geq 75$ & 17 & (26) & 0.5 & $0.22-1.27$ \\
\hline \multicolumn{5}{|l|}{ Comorbidity } \\
\hline No & 81 & (62) & Ref & \\
\hline 1 comorbid condition & 56 & (54) & 0.8 & $0.42-1.45$ \\
\hline$\geq 2$ comorbid conditions & 33 & (34) & 0.4 & $0.21-0.81$ \\
\hline Unknown & 15 & (48) & 0.7 & $0.27-1.65$ \\
\hline \multicolumn{5}{|l|}{ Primary tumor localization } \\
\hline Rectum & 85 & (55) & Ref & \\
\hline Colon & 100 & (48) & 0.9 & $0.37-2.26$ \\
\hline \multicolumn{5}{|l|}{ Adjuvant chemotherapy } \\
\hline No & 100 & (49) & Ref & \\
\hline Yes & 85 & (54) & 1.7 & $0.98-2.96$ \\
\hline \multicolumn{5}{|l|}{ Time to metastases (years) } \\
\hline$<1$ year & 43 & (43) & Ref & \\
\hline $1-2$ years & 71 & (55) & 1.5 & $0.78-2.82$ \\
\hline$\geq 2$ years & 71 & (53) & 1.2 & $0.60-2.30$ \\
\hline \multicolumn{5}{|l|}{ Period of diagnosis metastasis } \\
\hline $2005-2006$ & 41 & (37) & Ref & \\
\hline 2007-2008 & 78 & (58) & 3.0 & $1.62-5.70$ \\
\hline 2009-2011 & 66 & (57) & 3.3 & $1.67-6.74$ \\
\hline \multicolumn{5}{|l|}{ Number of organs affected } \\
\hline 1 organ & 85 & (54) & Ref & \\
\hline 2 organs & 59 & (46) & 0.5 & $0.29-0.91$ \\
\hline$\geq 3$ organs & 41 & (53) & 0.9 & $0.46-1.74$ \\
\hline \multicolumn{5}{|l|}{ First-line chemotherapy } \\
\hline Single agent chemotherapy & 32 & (23) & Ref & \\
\hline Combination chemotherapy & 153 & (70) & 9.6 & $5.43-17.05$ \\
\hline
\end{tabular}

$\mathrm{N}$; number of patients receiving bevacizumab in the first-line of systemic treatment

$\%$; percentage of patients receiving bevacizumab in the first-line of systemic treatment

$O R$ odds ratio, $\mathrm{Cl}$ confidence interval

Bold data; P-value $<0.05$ combination chemotherapy were more likely to receive bevacizumab than patients treated with single-agent chemotherapy (OR 9.666, 95 \% CI 5.43-17.05). Moreover, the odds for treatment with bevacizumab was higher for patients diagnosed with metastases in a recent time period than patients diagnosed with metastases shortly after the introduction of bevacizumab in Dutch guidelines (2005-2006). The probability to receive bevacizumab was lower for patients with $\geq 2$ comorbidities than patients without comorbidity (OR 0.4, $95 \%$ CI 0.21 $0.81)$ No association was observed between age and the use of bevacizumab. However, elderly patients ( $\geq 75$ years) were less likely to receive combination chemotherapy (OR $0.2,95 \%$ CI 0.11-0.30).

\section{Survival analysis}

As shown in Fig. 3, the addition of bevacizumab to first-line palliative chemotherapy was associated with an improved median overall survival, from 14 months (95\% CI 11-16) to 22 months (95\% CI 19-24) (log rank $p<0.0001)$. In the propensity score matched sample, including 60 patients (with bevacizumab $n=30$, without bevacizumab $n=30$ ), comparable results were found with a median overall survival of 13 months $(95 \% \mathrm{CI}$ 7.62-18.92) versus 25 months (95\%CI 7.62-18.92) (log rank $p<0.05$ ). In multivariable analysis, the addition of bevacizumab to palliative chemotherapy resulted in a reduced hazard ratio on death, in both the total study population (HR 0.6, $95 \%$ CI 0.45-0.73) and propensity score matched sample (HR 0.3; $95 \%$ CI 0.14-.079, Table 3). After stratification for the prescribed first-line chemotherapeutic regimen, the beneficial effect of the addition of bevacizumab was observed in the subset of patients receiving combination chemotherapy (HR 0.6; $95 \% \mathrm{CI}$ $0.40-0.81$ ), but not in patients treated with single-agent chemotherapy (HR 0.9, 95 \% CI 0.60-1.54).

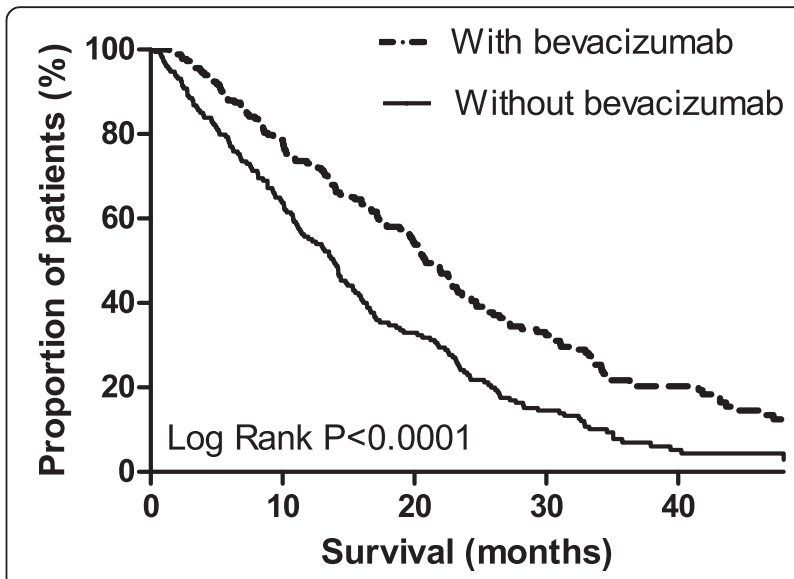

Fig. 3 Overall survival according to the addition of bevacizumab to first-line systemic therapy $(n=361)$ 
Table 3 Multivariable Cox regression analysis modelling the independent effect of additional bevacizumab on the risk of death, adjusted for all factors listed

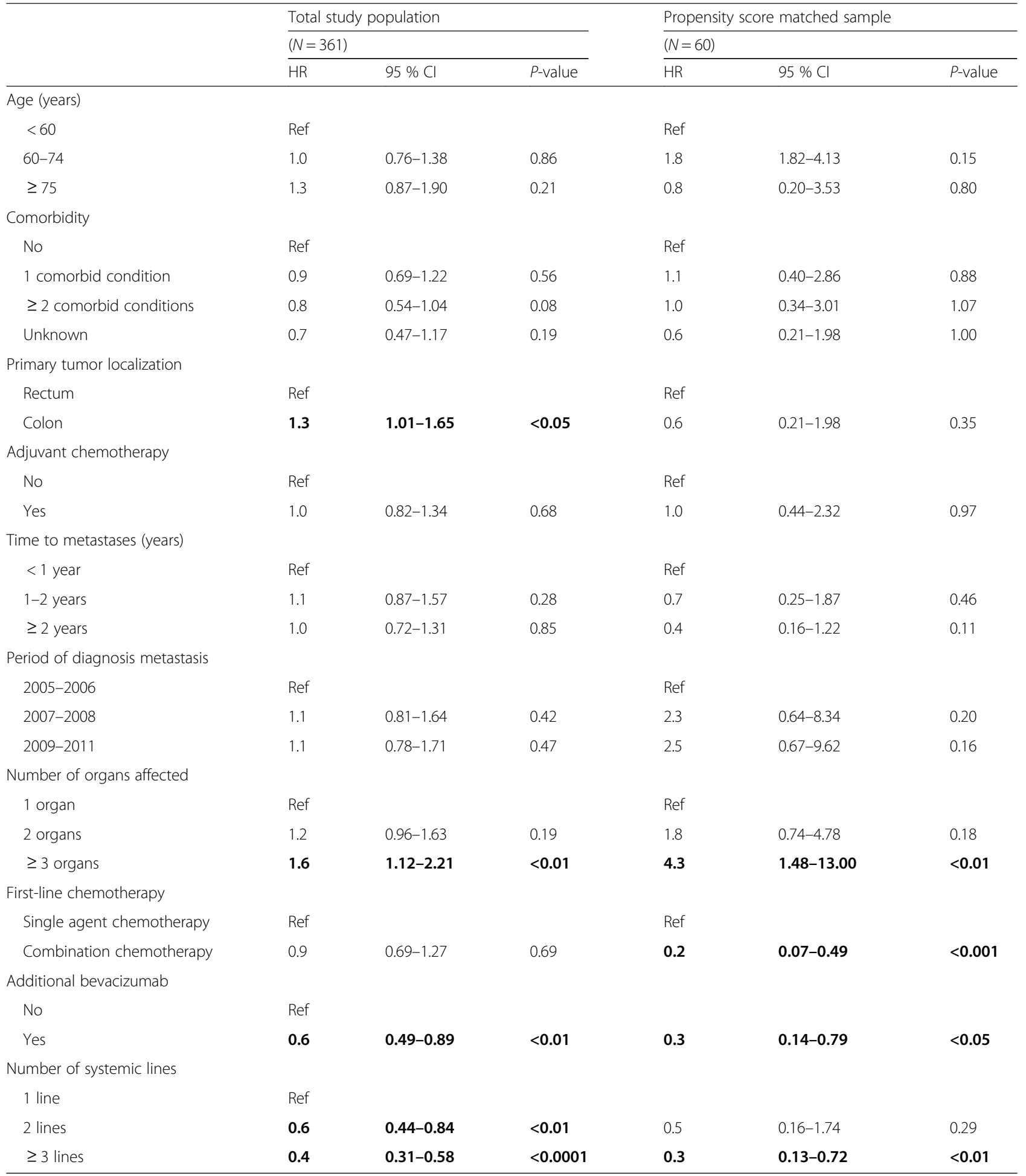

$N$ number of patients, $H R$ hazard ratio, $\mathrm{Cl}$ confidence interval Bold data; P-value $<0.05$

\section{Discussion}

To our knowledge, this is the first study providing population-based data on the use of bevacizumab in the metachronous setting, which has been suggested to differ from synchronous manifestation of disseminated disease with respect to tumor biology and prognostics [9-11]. 
Bevacizumab was prescribed in approximately half of the patients with metachronous metastases receiving first-line palliative treatment between 2005 and 2011 in the southern part of the Netherlands, achieving a median overall survival of 22 months. Prescription of bevacizumab varied significantly between hospitals of diagnosis and depended on the prescribed chemotherapeutic regimen.

The inter-hospital variation in the adoption of bevacizumab as observed in our study may reflect differences in policy and attitude towards the use of this antiangiogenic agent in daily practice [12]. Bevacizumab was FDA-approved following the landmark publication by Hurwitz et al in which a survival benefit was demonstrated in patients treated with irinotecan, bolus fluorouracil and leucovorin (IFL) [6]. However, by the time bevacizumab was adopted in clinical practice, a shift towards oxaliplatin-based chemotherapy had taken place in the Netherlands [13-15]. Due to the initial absence of efficacy data in addition to these oxaliplatin containing regimens and the controversial results that were reported later on [16], the role of bevacizumab remained a highly debated topic. Also, the recent introduction of antibodies against epidermal growth factor receptors (EGFR) [17] strengthened the debate, as the question was raised which targeted agent should be preferred in the first-line systemic treatment [18]. In order to prevent an expanding gap between "believers" and "nonbelievers" in the current era of evolving treatment options for mCRC, ongoing efforts are needed to establish an evidence based opinion on the use of bevacizumab.

In line with the Dutch guidelines, the majority of patients with metachronous metastases received oxaliplatinbased chemotherapy (CAPOX or FOLFOX) whereas fewer patients were treated with single-agent chemotherapy (mostly capecitabine). Elderly patients and patients with multiple comorbidities were less often considered candidates for treatment with oxaliplatin-based chemotherapy, reflecting the generally accepted opinion that individual components of a systemic regimen should be selected on a number of factors, including patient related factors such as age, performance status and comorbidity [19]. Moreover, we observed that adjuvant chemotherapy influenced the choice of chemotherapy for the treatment of metachronous metastases. If adjuvant chemotherapy was prescribed, patients were less likely to receive combination chemotherapy as palliative treatment. This probably reflects the persistence of troublesome oxaliplatin induced polyneuropathy after adjuvant chemotherapy [20]. Since 2004, adjuvant oxaliplatin-based chemotherapy is considered the standard treatment schedule in the Netherlands for high risk stage II and stage III colonic tumors [21, 22]. For rectal tumors, however, adjuvant chemotherapy is generally not recommended, which probably explains the relatively higher proportion of oxaliplatin- based regimens for the treatment of metastases in this subset of patients.

The likelihood of treatment with bevacizumab was shown to depend strongly on the prescribed chemotherapeutic regimen for the metastatic disease. If a patient was considered a candidate for combination-chemotherapy, bevacizumab was prescribed in approximately $70 \%$ of the cases. On the opposite, if single-agent chemotherapy was prescribed, only $23 \%$ of the patients received bevacizumab. These findings are in line with results from observational cohort studies in the U.S. [13-15]. Of course, it could be speculated that bevacizumab was prescribed in combination with further lines of chemotherapy, as the results from the CAIRO III study revealed equal results for combined and sequential treatment chemotherapy strategies [23]. However, very few patients included in the current study received bevacizumab in further lines of treatment (data not shown).

In accordance with observations from the current literature in which age has been identified as one of the most important factors when deciding the type of therapy for patients with $\mathrm{mCRC}[24,25]$, we observed that elderly patients ( $\geq 75$ years) were less likely to receive combination-chemotherapy than younger patients. However, advanced age did not influence the probability to receive bevacizumab if adjustments were made for the prescribed chemotherapeutic regimen. Thus, age influenced primarily the choice of cytostatic backbone. This observation reflects the lack of data on the benefit-risk ratio of combination-chemotherapy regimens in older patients. It has been shown that the bevacizumab related adverse events do not increase with age, except for arterial thromboembolic events [26]. However, for this complication other patient related factors appeared to be stronger predictive factors than age [26]. Bevacizumab should therefore be considered a potential therapeutic option for elderly patients with $\mathrm{mCRC}$ and age alone should not be considered an absolute contraindication [27].

The addition of bevacizumab to first-line palliative therapy was associated with a median overall survival of 22 months, which is consistent with reports from observational studies on mCRC from the period 2002-2007 [13-15]. Of course, this observed improvement in overall survival with the addition of bevacizumab was biased by the prescription of more potential cytostatic backbone regimens in the presence of bevacizumab, and by patient selection by the treating physician. Nevertheless, after adjustment for important prognostic factors such as the prescribed chemotherapeutic regimen, a reduced hazard of death was observed in patients receiving additional bevacizumab. Moreover, results remained present in the propensity score matched sample, in which an effort is made to limit potential endogeneity bias. After stratification for the type of chemotherapy, the beneficial effect of 
additional bevacizumab achieved significance only in the subset of patients treated with combinationchemotherapy, probably because patient numbers were too small in the subset of single-agent backbone therapy. Although these non-randomized observational data should be interpreted with caution, together with the demonstrated benefit of bevacizumab across chemotherapy regimens in several RCTs [6, 16, 28-30] and observational studies [13-15], they strengthen the suggestion that bevacizumab is likely to add activity to various chemotherapy regimens with which it is combined.

Despite the accurate and concise patient registration, use of the ECR also implies limitations to our data. No data on relevant prognostic factors such as extent of metastatic burden were available. Moreover, data on patient and tumor characteristics such as comorbidity are registered by registration personnel approximately 6-9 months after primary tumor diagnosis. Therefore, it is not possible to provide data on the specific comorbidities present at the time of treatment for metachronous metastases.

\section{Conclusions}

In conclusion, in this population-based study it was revealed that addition of bevacizumab to the first line treatment of metachronous metastases of CRC is likely to be an independent beneficial factor for overall survival in patients receiving oxaliplatin containing chemotherapy. Moreover, a significant inter-hospital difference in the prescription of bevacizumab was found, reflecting differences in attitude towards and policies in the use of bevacizumab in clinical practice. Ongoing efforts should be made to further define the position of targeted agents in the treatment of metachronous metastases from CRC.

\section{Abbreviations}

Cl: confidence interval; CRC: colorectal carcinoma; ECR: Eindhoven cancer registry; HR: hazard ratio; mCRC: metastatic colorectal carcinoma.

\section{Competing interests}

The authors declare that they have no competing interests.

\section{Authors' contributions}

$L R, V L, G C, I H, Y G$ designed the study. $L R$ and $Y G$ interpreted the data and performed the statistical analyses. $L R, Y G, I H, G C$ and $V L$ drafted the manuscript. GV,LB, OL, VL, IH, GC and VL reviewed the manuscript. All authors read and approved the final manuscript.

\section{Acknowledgements}

The authors thank the registration personnel of the Eindhoven Cancer Registry for their dedicated data collection. The authors also thank the hospitals located in the Eindhoven Cancer Registry area: Amhpia Hospital, Breda; Bernhoven Hospital, Veghel and Oss; Catharina Hospital, Eindhoven; Elkerliek Hospital, Helmond; Jeroen Bosch Hospital, 's-Hertogenbosch; Maxima Medical Centre, Eindhoven and Veldhoven; St. Anna Hospital, Geldrop; St. Elisabeth Hospital, Tilburg; TweeSteden Hospital, Tilburg and Waalwijk; VieCuri Medical Centre, Venlo and Venray.

\section{Funding}

The study was financed by a grand from the Netherlands Organisation for Health Research and Development (ZonMw), project numbers 152002012 and 152001022 and was supported by an unrestricted grant from Roche Pharameuticals. Both funders did not have any involvement in the study design, data collection, data analysis, data interpretation and writing of the report. Moreover, the decision to submit for publication was made independently by the authors.

\section{Author details}

'Department of Oncology, Catharina Hospital, Michelangelolaan 2, 5623EJ, Eindhoven, The Netherlands. ${ }^{2}$ Netherlands Comprehensive Cancer Organization (IKNL), Godebaldkwartier 419, 3511DT, Utrecht, The Netherlands. ${ }^{3}$ Department of Surgery, Catharina Hospital, Michelangelolaan 2, 5623EJ, Eindhoven, The Netherlands. ${ }^{4}$ Department of Oncology, Amphia Hospital, Langendijk 75, 4819EV, Breda, The Netherlands. ${ }^{5}$ Department of Oncology, Maxima Medical Centre, De Run 4600, 5504DB, Veldhoven, The Netherlands. ${ }^{6}$ Department of Oncology, Elisabeth-TweeSteden Hospital, Hilvarenbeekse Weg 60, 5022GC, Tilburg, The Netherlands. 'Department of Public Health, Erasmus MC University Medical Centre, Wytemaweg 8, 3015CN, Rotterdam, The Netherlands.

Received: 4 September 2015 Accepted: 10 February 2016

Published online: 16 February 2016

\section{References}

1. Lemmens $V$, van Steenbergen $L$, Janssen-Heijnen $M$, Martijn $H$, Rutten $H$, Coebergh JW. Trends in colorectal cancer in the south of the Netherlands 1975-2007: rectal cancer survival levels with colon cancer survival. Acta Oncol. 2010;49(6):784-96.

2. Meulenbeld HJ, van Steenbergen LN, Janssen-Heijnen ML, Lemmens VE, Creemers GJ. Significant improvement in survival of patients presenting with metastatic colon cancer in the south of The Netherlands from 1990 to 2004. Ann Oncol. 2008;19(9):1600-4.

3. van der Pool AE, Damhuis RA, ljzermans JN, de Wilt JH, Eggermont AM, Kranse $\mathrm{R}$, et al. Trends in incidence, treatment and survival of patients with stage IV colorectal cancer: a population-based series. Colorectal Dis. 2012;14(1):56-61.

4. McArdle C. ABC of colorectal cancer: effectiveness of follow up. BMJ. 2000; 321(7272):1332-5.

5. BOM C. Raltitraxed, oxaliplatin en irinotecan door commissie BOM beoordeeld. Medische Oncologie. 2001;1:30-3.

6. Hurwitz H, Fehrenbacher L, Novotny W, Cartwright T, Hainsworth J, Heim W Berlin J, Baron A, Griffing S, Holmgren E, et al. Bevacizumab plus irinotecan, fluorouracil, and leucovorin for metastatic colorectal cancer. N Engl J Med. 2004;350(23):2335-42.

7. UICC. TNM Classification of Malignant Tumours. 7th ed. New York: WileyBlackwell; 2009.

8. BOM C. Bevacizumab bij het colorectaal carcinoom en docetaxel bij het hormoonrefractair prostaatcarcinoom. Medische Oncologie. 2005;2:43-9.

9. Mekenkamp L, Koopman M, Teerenstra S, van Krieken JH, Mol L, Nagtegaal ID, et al. Clinicopathological features and outcome in advanced colorectal cancer patients with synchronous vs metachronous metastases. $\mathrm{Br} J$ Cancer. 2010;103(2):159-64.

10. Kumar R, Price TJ, Beeke C, Jain K, Patel G, Padbury R, Young GP, Roder D, Townsend A, Bishnoi S, et al. Colorectal Cancer Survival: An Analysis of Patients With Metastatic Disease Synchronous and Metachronous With the Primary Tumor. Clin Colorectal Cancer 2013;13(2):87-93.

11. Slesser AA, Georgiou P, Brown G, Mudan S, Goldin R, Tekkis P. The tumour biology of synchronous and metachronous colorectal liver metastases: a systematic review. Clin Exp Metastasis. 2013;30(4):457-70.

12. Macedo LT, da Costa Lima AB, Sasse AD. Addition of bevacizumab to firstline chemotherapy in advanced colorectal cancer: a systematic review and meta-analysis, with emphasis on chemotherapy subgroups. BMC Cancer. 2012;12:89.

13. Van Cutsem E, Rivera F, Berry S, Kretzschmar A, Michael M, DiBartolomeo M, Mazier MA, Canon JL, Georgoulias V, Peeters M, et al. Safety and efficacy of first-line bevacizumab with FOLFOX, XELOX, FOLFIRI and fluoropyrimidines in metastatic colorectal cancer: the BEAT study. Ann Oncol. 2009;20(11):1842-7.

14. Kozloff M, Yood MU, Berlin J, Flynn PJ, Kabbinavar FF, Purdie DM, Ashby MA Dong W, Sugrue MM, Grothey A, et al. Clinical outcomes associated with 
bevacizumab-containing treatment of metastatic colorectal cancer: the BRiTE observational cohort study. Oncologist. 2009;14(9):862-70.

15. Meyerhardt JA, Li L, Sanoff HK, Carpenter W, Schrag D. Effectiveness of bevacizumab with first-line combination chemotherapy for Medicare patients with stage IV colorectal cancer. J Clin Oncol. 2012;30(6):608-15.

16. Saltz LB, Clarke S, Diaz-Rubio E, Scheithauer W, Figer A, Wong R, Koski S, Lichinitser M, Yang TS, Rivera F, et al. Bevacizumab in combination with oxaliplatin-based chemotherapy as first-line therapy in metastatic colorectal cancer: a randomized phase III study. J Clin Oncol. 2008;26(12):2013-9.

17. Cunningham D, Humblet $Y$, Siena $S$, Khayat $D$, Bleiberg H, Santoro A, Bets $D$, Mueser M, Harstrick A, Verslype C, et al. Cetuximab monotherapy and cetuximab plus irinotecan in irinotecan-refractory metastatic colorectal cancer. N Engl J Med. 2004;351(4):337-45.

18. BOM C. Cetuximab voor eerstelijns behandeling gemetastaseerd en/of irresectabel colorectaalcarcinoom zonder KRAS-genmutatie (KRASwt). Medische Oncologie. 2011;5:29-35.

19. Schmoll HJ, Van Cutsem E, Stein A, Valentini V, Glimelius B, Haustermans K, Nordlinger B, van de Velde CJ, Balmana J, Regula J, et al. ESMO Consensus Guidelines for management of patients with colon and rectal cancer. a personalized approach to clinical decision making. Ann Oncol. 2012; 23(10):2479-516.

20. Mols F, Beijers T, Lemmens V, van den Hurk CJ, Vreugdenhil G, van de Poll-Franse LV. Chemotherapy-induced neuropathy and its association with quality of life among 2- to 11-year colorectal cancer survivors: results from the population-based PROFILES registry. J Clin Oncol. 2013;31 (21):2699-707.

21. BOM C. Oxaliplatine, 5 -fluorouracil en leucovorin als adjuvante behandeling bij coloncarcinoom stadium II en III (MOSAIC-studie). Medische Oncologie. 2004:4:45-7.

22. Andre T, Boni C, Mounedji-Boudiaf L, Navarro M, Tabernero J, Hickish T, Topham C, Zaninelli M, Clingan P, Bridgewater J, et al. Oxaliplatin, fluorouracil, and leucovorin as adjuvant treatment for colon cancer. N Engl J Med. 2004;350(23):2343-51.

23. Koopman M, Antonini NF, Douma J, Wals J, Honkoop AH, Erdkamp FL, de Jong RS, Rodenburg CJ, Vreugdenhil G, Loosveld OJ et al. Sequential versus combination chemotherapy with capecitabine, irinotecan, and oxaliplatin in advanced colorectal cancer (CAIRO): a phase III randomised controlled trial. Lancet. 2007:370(9582):135-42.

24. McKibbin T, Frei CR, Greene RE, Kwan P, Simon J, Koeller JM. Disparities in the use of chemotherapy and monoclonal antibody therapy for elderly advanced colorectal cancer patients in the community oncology setting. Oncologist. 2008;13(8):876-85.

25. Khattak MA, Townsend AR, Beeke C, Karapetis CS, Luke C, Padbury R, et al. Impact of age on choice of chemotherapy and outcome in advanced colorectal cancer. Eur J Cancer. 2012:48(9):1293-8.

26. Kozloff MF, Berlin J, Flynn PJ, Kabbinavar F, Ashby M, Dong W, et al. Clinical outcomes in elderly patients with metastatic colorectal cancer receiving bevacizumab and chemotherapy: results from the BRiTE observational cohort study. Oncology. 2010;78(5-6):329-39.

27. Sclafani F, Cunningham D. Bevacizumab in elderly patients with metastatic colorectal cancer. J Geriatr Oncol. 2014:5(1):78-88.

28. Alves A, Panis Y, Mathieu P, Mantion G, Kwiatkowski F, Slim K. Postoperative mortality and morbidity in French patients undergoing colorectal surgery: results of a prospective multicenter study. Arch Surg. 2005; 140(3):278-83. discussion 284.

29. Kabbinavar FF, Schulz J, McCleod M, Patel T, Hamm JT, Hecht JR, et al. Addition of bevacizumab to bolus fluorouracil and leucovorin in first-line metastatic colorectal cancer: results of a randomized phase II trial. J Clin Oncol. 2005;23(16):3697-705.

30. Tebbutt NC, Wilson K, Gebski VJ, Cummins MM, Zannino D, van Hazel GA Robinson B, Broad A, Ganju V, Ackland SP, et al. Capecitabine, bevacizumab, and mitomycin in first-line treatment of metastatic colorectal cancer: results of the Australasian Gastrointestinal Trials Group Randomized Phase III MAX Study. J Clin Oncol. 2010;28(19):3191-8.

\section{Submit your next manuscript to BioMed Central and we will help you at every step:}

- We accept pre-submission inquiries

- Our selector tool helps you to find the most relevant journal

- We provide round the clock customer support

- Convenient online submission

- Thorough peer review

- Inclusion in PubMed and all major indexing services

- Maximum visibility for your research

Submit your manuscript at www.biomedcentral.com/submit
() BioMed Central 